\title{
Industrial concentration and price-cost margin of the micro and small enterprises in the Indonesian food and beverages industry
}

\author{
Maman Setiawan ${ }^{1, *}$, Muhammad Purnagunawan ${ }^{1}$, Nury Effendi ${ }^{1}$, Rina Indiastuti ${ }^{1}$ \\ ${ }^{1}$ Department of Economics, Faculty of Economics and Business, Padjadjaran University, Indonesia \\ *Corresponding author: maman.setiawan@unpad.ac.id
}

\begin{abstract}
This research investigates the relationship between industrial concentration and price-cost margin of the micro and small enterprises (MSEs) in the Indonesian food and beverages industry. This research uses the survey data of the MSEs from the Bureau of Central Statistic during the period from 2011 to 2014. This research uses panel data econometrics to estimate the relationship between the variables.

This research found that there is a low industrial concentration of the MSEs in the Indonesian food and beverages industry. In spite of this, there is a positive average price-cost margin of the MSEs in the industry. The industrial concentration affects negatively the price-cost margin which suggests the policy maker to increase the size of the MSEs to gain more efficiency.
\end{abstract}

Keywords: price-cost margin, industrial concentration, Indonesian micro and small enterprises, food and beverages industry

\section{INTRODUCTION}

Indonesian micro and small enterprises (MSEs) of the food and beverages industry contribute significantly to the Indonesia economy with the output contribution of this sector reached about $35 \%$ to the total output in the micro and small industry in 2014 (BPS, 2015). In addition, the number of MSEs of this sector is higher than the big firms, but the contribution of the MSEs to the GDP is less than big firms ${ }^{1}$.

Naturally, the higher number of MSEs indicates higher competition in the industry which may cause low mark up of the firms, since the larger number of firms in the Indonesian MSEs may cause the reduction of the ability of firms to increase the price over the cost. Firms tend to be more efficient by reducing cost and increasing innovation to attract more consumers rather than using the market power. In line with this, Setiawan et al. (2016) found that the higher competition increased the technical efficiency of the Indonesian micro, small and medium enterprises in Bandung Region in Indonesia.

Previous research has investigated the relationship between competition and mark up in the Indonesian economy. Setiawan et al. (2012a, 2013) found that the higher industrial concentration increased the mark up represented by the price-cost margin. The higher number of firms is found to be correlated with the lower industrial concentration. Also Setiawan et a. (2015a) found that the high mark-up was caused by the ability of firms to keep the higher prices in the highly concentrated industries.

Also research related to the relationship between the industrial concentration and the price-cost margin has been done in other countries (see Sizrazi, 1974; Ghosal, 1989; and Prince and Thurik, 1992;

\footnotetext{
${ }^{1}$ The number of micro, small and medium enterprises reaches more than $99 \%$ of the total firms, but the contribution to the GDP only reaches about $60 \%$ and the rest comes from the big firms.
} 
Dickson, 2005). Regarding the Asian Countries, Gan (1978) and Kalirajan (1993) found that there was a positive and significant influence of industrial concentration on the price-cost margin in Malaysian manufacturing. Furthermore, Go, Kamerschen, and Delorme (1999) also observed a positive relationship between the industrial concentration and the price-cost margin in Philippines manufacturing industries. Most of the research conducted to date investigated medium and big firms of the Indonesian manufacturing industry. The information about the relationship between the industrial concentration and the price-cost margin in the MSEs will provide further insight for the policy makers on whether the firms in the industry should be larger in size to gain more efficiency through the cost of lessening of the competition. Therefore, the investigation of the effect of industrial concentration on industrial price-cost margin in the Indonesian MSEs is relevant for policy makers.

This research investigates the industrial concentration and price-cost margin of the micro and small enterprises in the Indonesian MSEs. Also, this research is a fresh estimate of the relationship between industrial concentration and price-cost margin in the sector. This research has policy implication for the MSEs development in Indonesia. The findings of the positive relationship between industrial concentration and price-cost margin will suggest the policy maker to encourage the competition in the MSEs of the Indonesian food and beverages sector.

\section{LITERATURE REVIEW}

This research estimates the effect of the industrial concentration on the price-cost margin in the industry. The higher industrial concentration may lead to the higher industrial price-cost margin (Bain, 1951; Gupta, 1983). Furthermore, Saving (1970), Cowling and Waterson (1976), Fischer and Kamerschen (2003a, 2003b), and Kamerschen, Klein, and Porter (2005) run a mathematical derivation to prove the existence of the effect of the industrial concentration on the price-cost margin.

Research investigating the relationship between industrial concentration and price-cost margin or mark-up of the firms has been conducted by many researchers, but the research is mostly done for the medium and big firms. Few studies have been investigated the relationship between the two variables in Indonesian medium and big firms of the manufacturing industry. Setiawan et al. (2012a, 2013) observed the relationship between the industrial concentration and price-cost margin for 54 subsectors of the Indonesian food and beverages industry. They found that the industry was highly concentrated with high price-cost margin. Furthermore, there was a positive effect of the industrial concentration on the price-cost margin.

Regarding the relationship between industrial concentration and price-cost margin in the MSEs, Prince and Thurik (1995) found that there was a negative effect of the seller's concentration on the price-cost margin. They investigated small firms of the 3-digit ISIC level in the Ducth manufacturing industry for the period 1975-1986. Furthermore, there is a rare research investigating the relationship betwen the two variables in the Indonesian MSEs. For example, Setiawan et al. (2015b) only investigated the competitiveness of the SMEs in micro, small and medium enterprises in Cimahi region of Indonesia. Also, Setiawan et al (2016) investigated the effect of the competition measured by number of competitor on the technical efficiency. Therefore, research investigating the effect of the industrial concentration on the pricecost margin of the Indonesian MSEs will give contribution to the literature.

\section{MEASURING THE VARIABLES}

This research uses the commonly measures of industrial concentration i.e. the concentration ratio for $\mathrm{n}$ firms $\left(C R_{n}\right)$ and the Herfindahl-Hirshman Index (HHI) as suggested by Setiawan et a. (2012a, $2012 b, 2013,2016)$. The measures are based on the market share of the firms and calculated by the following formulas:

$$
\begin{aligned}
& \mathrm{CR}_{\mathrm{j}}=\sum_{\mathrm{i}=1}^{4} \mathrm{MS}_{\mathrm{i}} \\
& \mathrm{HH} \mathrm{j}_{\mathrm{j}}=\sum_{\mathrm{i}=1}^{\mathrm{n}}\left(\mathrm{MS}_{\mathrm{i}}\right)^{2}
\end{aligned}
$$

where $j=1,2, \ldots, m$ is the index of the subsector, $i$ $=1,2, \ldots n$ indexes firm $i$ in a subsector, and $M S_{i}$ is the market share of firm $i$ in its respective 
subsector. $C R 4$ is the collective share of the four largest firms in a subsector and $H H I_{j}$ includes the inequality of distribution of market shares among all firms in subsector $j$. The use both of the CR4 and the Herfindahl-Hirschman Index (HHI) can cover the limitation in the calculation, since they complement each other.

Moreover, the price-cost margin (PCM) is calculated according to the formula proposed by Domowitz, Hubbard, and Petersen (1986), Prince and Thurik (1992), and Setiawan et al. (2012a, 2013, 2016). This formula considers the changes in inventories ( $\Delta$ Inventories), as follows:

$$
\mathrm{PCM}=\frac{\text { Value Added }- \text { Cost of Labor }+\Delta \text { Inventores }}{\text { Sales }+\Delta \text { Inventorés }}
$$

Where value added is calculated by sales minus intermediate inputs except labor cost.

\section{EMPIRICAL MODEL}

This paper uses econometric models to investigate the relationship between industrial concentration and the price-cost margin. This paper also uses capital intensity measured by capital-labor ratio that can affect the price-cost margin as suggested by Prince and Thurik (1995). The final model of the industrial concentration-price-cost margin model is formulated as follows:

$$
\mathrm{PCM}_{\mathrm{jt}}=\gamma_{\mathrm{i}}+\theta_{1} \mathrm{IC}_{\mathrm{jt}}+\theta_{2} \mathrm{CLR}_{\mathrm{it}}+\mathrm{v}_{\mathrm{it}}
$$

where $j$ and $t$ are indexes of subsector and time, respectively. CLR is the capital intensity (measured by capital-labor ratio), and PCM is the price-cost margin.

Regarding the relationship between industrial concentration and the price-cost margin, this research considers the endogeneity problem in the variable of industrial concentration (Clarke and Davis, 1982; Kalirajan, 1993; Setiawan et al, 2012a, 2012b, 2013, 2016). Therefore, this paper applies some instrumental variables for solving the endogeneity problem of the industrial concentration. The instrumental variables chosen are based on the works of Go, Kamerschen, and Delorme (1999); Delorme, Kamerschen, Klein, and Voeks (2002) and Setiawan et al. (2012a, 2012b, 2013, 2016). The main instrumental variables used are industry size (Size) and capital output ratio (COR). In addition, equation (1) is estimated using unbalanced panel data techniques with random effect models based on the Hausman test (1978).

\section{DATA}

This research uses the data from the Indonesian Bureau of Central Statistics (BPS) for the period from 2011 to 2014. The data is sourced from the survey of micro and small enterprises. This research uses unit of MSEs classified by 5 digits ISIC level in the food and beverages industry. This research uses only 10 subsectors listed in the Indonesian food and beverages industry of the MSEs survey data.

\section{Table 1. Descriptive statistics of the variables from 2011-2014}

From Table 1, it is seen that MSEs of the Indonesian food and beverages industry is not concentrated with the average industrial concentration of 0.259 and 0.066 for the CR4 and HHI measures, respectively. In spite of this, there is high variation of the CR4 and HHI for the industry with the standar deviation of 0.220 and 0.143 , respectively. Furthermore, average price-cost margin reaches 0.121 indicating that the MSEs still have positive profit. In spite of this, there is also high variation of the price-cost margin (PCM) with the coefficients of the standar deviation reaches to 0.397 or larger than the average PCM.

\section{RESULTS}

Furthermore, Table-2 shows the mean of price-cost margin and industrial concentration between the years in the period from 2011 to 2014. Average PCM has a fluctuative trend during the period of estimation. In spite of this, the average PCM is better during the period 2013-2014 compared to the period 2011-2012. Moreover, there is a trend of the negative relationship between the industrial concentration and price-cost margin during the period of estimation. For example, the average industrial concentration during the period 20112012 is higher than the average industrial concentration during the period 2013-2014. Correspondingly, the average price-cost margin is higher during the period 2013-2014 than the one during the period 2011-2012. 


\section{Table 2. Trend of The Technical Efficiency Score} and Industrial Concentration

Table 3 provides the estimation of the effect of the industrial concentration on the price-cost margin. The coefficients of the CR4 and HHI are -1.141 and -1.477 indicating that the increase of the CR4 and HHI by 1 unit, decreases average price-cost margin by 1.141 and 1.477 unit, ceteris paribus. The CR4 and and HHI significantly affect the price-cost margin at the $1 \%$ critical level, respectively. This suggests that the larger size of firms can increase the efficiency larging the gap between price and the cost. The economy of scale may also apply in this situation. This result supports the finding of the Prince and Thurik (1995) who found that the industrial concentration affected price-cost margin negatively.

\section{Table 3. Results of the Relationship Between Industrial Concentration and Price-cost Margin}

Moreover, capital intensity (CLR) affects positively the price-cost margin. The coefficients of CLR are 0.017 and 0.019 for the model with CR4 and HHI measures, respectively. These indicate that the increase of the CLR by 1 unit, increases pricecost margin by 0.017 and 0.019 unit for the model with CR4 and HHI measures, respectively. This is also in line with the finding of Prince and Thurik (1995) who found positive relationship between capital intensity and price-cost margin.

\section{CONCLUSION AND POLICY IMPLICATION}

This research investigates the relationship between industrial concentration and price-cost margin of the micro and small enterprises in the Indonesian food and beverages industry during the period from 2011-2014. This research finds that there is a low industrial concentration of the micro and small enterprises in the Indonesian food and beverages industry. This suggests that there is a high competition between the micro and small firms in the industry. In spite of this, the average price cost margin is positive with better price-cost margin during the period 2013-2014 compared to the period 2011-2012.

Furthermore, the industrial concentration has a negative effect on the price-cost margin indicating that the lower competition may reduce the pricecost margin. This happens because of the size affecting the efficiency. Regarding that, policy maker may want to increase the size of the micro and small firms to the size of the medium firms to increase efficiency of the firms and the ability of the MSEs to compete with the medium and big firms.

\section{REFERENCES}

Bain, J. S. (1956) Barriers to New Competition, Harvard University Press, Cambridge, MA.

Bain, J.S. (1951) Relation of profit rate to industry concentration : American manufacturing, 19361940, Quarterly Journal of Economics, 65, pp. 293-325

Barro, Robert J. and Sala-I-Martin, Xavier (1992) Convergence, Journal of Political Economy, 100, pp. 223-252

Brozen, Y., (1982) Concentration, Mergers, and Public Policy, Macmillan, New York.

Bureau of Central Statistics Republic of Indonesia (2015), UMKM Report

Clarke, Roger and Davies, Stephen W. (1982) Market structure and price-cost margins, Economica, New Series, 49(195), pp. 277-287

Collins, Norman R. and Preston, Lee E. (1969) Concentration and price-cost margin in food manufacturing industries, The Journal of Industrial Economics, 14(3), pp. 226-242

Cowling, Keith and Waterson, Michael (1976) Price-cost margin and market structure, Economica, 43, pp. 267-274

Delorme Jr., Charles D., Kamerschen, David R., Klein, Peter G. and Voeks, Lisa Ford (2002) Structure, conduct, and performance : a simultaneous equations approach, Applied Economics, 34, pp. 2135-2141

Dickson, Vaughan (2005) Price-cost margins, prices, and concentration in US manufacturing: a panel study, Applied Economics Letters, 12(2), pp. 79-83

Domowitz, Ian, Hubbard, R. Glenn and Petersen, Bruce C. (1986) Business cycles and the relationship between concentration and pricecost margins, The RAND Journal of Economics, 17(1), pp. 1-17

Domowitz, Ian, Hubbard, R. Glenn and Petersen, Bruce C. (1988) Market structure and cyclical fluctuations in U.S. Manufacturing, The Review of Economics and Statistics, 70(1), pp.55-66 
Domowitz, Ian, Hubbard, R. Glenn, and Petersen, Bruce C. (1993) Market structure and cyclical fluctuations in U.S. manufacturing : Reply, The Review of Economics and Statistics, 75(4), pp. 734-735

Fischer, Thorsten, and Kamerschen, David R. (2003a) Measuring competition in the U.S. airline industry using the Rosse-Panzar test and cross-sectional regression analysis, Journal of Applied Economics, VI(1), pp. 73-93

Fischer, Thorsten, and Kamerschen, David R. (2003b) Price-cost margins in the US airline industry using a conjectural variation approach, Journal of Transport Economics and Policy, 37(2), pp. 227-259

Gan Wee Beng and Yen, Tham Siew (1977) Market structure and price-cost margins in Malaysian manufacturing industries, The Developing Economies, 15(3), pp. 280-292

Ghosal, Vivex (1989) Market structures, price-cost margins, and unionism: an empirical note, Economics Letters, 29, pp. 179-182

Go, Gerald L., Kamerschen, David R. and Delorme, Charles D. (1999) Market structure and pricecost margin in Phillipine manufacturing industries, Applied Economics, 31, pp.857-864

Gupta, Vinod K. (1983) A simultaneous determination of structure, conduct, and performance in Canadian manufacturing, Oxford Economic Paper, 35(2), pp. 281-301

Hausman, J.A.(1978). Specification Tests in Econometrics, Econometrica, 46, 6), pp. 12511271

Kalirajan, K.P. (1993) On the simultaneity between market concentration and profitability : the case of a small-open developing country, International Economic Journal, 7(1), pp. 3148

Kamerschen, David R., and Jae-Hee Park (1993a) An alternative approach to market structure and the mark-up ratio, Applied Economics, 25, pp. 111-124

Kamerschen, David R., and Jae-Hee Park (1993b) Market structure and cyclical fluctuations in U.S. manufacturing : Comment, The Review of Economics and Statistics, 75(4), pp. 732-734

Kamerschen, David R. (1994) Testing for antitrust market definition under the Federal Government Guidelines, Journal of Legal Economics, 4(1), pp. 1-10
Kamerschen, David R., Klein, Peter G., and Porter, David V. (2005) Market structure in the US electricity industry : a long term perspective, Energy Economics, 27, pp. 731-751

Levenstein, Margaret C. (2003) Review of george symeonidis, the effects of competition: cartel policy and the evolution of strategy and structure in British industry, EH.Net Economic History Services, July 9

Liebenberg, Andre P. and Kamerschen, David R. (2008) Structure, conduct, and performance analysis of the south African auto insurance market: 1980-2000, South African Journal of Economics, 76(2), pp. 228-238

Prince, Y.M. and Thurik, A.R. (1992). Price-cost Margins in Dutch Manufacturing, De Economist 140, 3, pp. 1-26

Prince, Y.M. and Thurik, A.R. (1995). Do Small Firms' Price Cost Margin Follows those of Large Firms? Bulletin of Economic Research, 47, pp. $321-327$

Saving, Thomas R. (1970) Concentration ratios and the degree of monopoly, International Economic Review, 11(1), pp. 139-146

Setiawan, M, Emvalomatis, G, Oude Lansink, A (2012a) Industrial Concentration and Price Cost Margin in Indonesian Food and Beverages Industry, Applied Economics, 44, pp.3805-3814

Setiawan, M., Emvalomatis, G.. Oude Lansink, A. (2012b). The Relationship Between Technical Efficiency and Industrial Concentration : Evidence from the Indonesian Food and Beverages Industry, Journal of Asian Economics, 23 (4), pp. 466-75

Setiawan, M, Emvalomatis, G, Oude Lansink, A (2013b) Structure, Conduct, and Performance: Evidence From the Indonesian Food and Beverages Industry, Empirical Economics, 45, pp. 1149-1165

Setiawan, M, Emvalomatis, G, Oude Lansink, A (2016), Survey of the Industrial Concentration and Price-cost of the Indonesian Manufacturing, International Economic Journal, 30(1), pp. 123146

Setiawan, M., Indiastuti, R. Effendi, N., and Indrawati, D. (2016). Technical Efficiency and Environmental Factors of the Micro, Small and Medium Enterprises in Bandung City, International Journal of Globalization and Small Business, Vol. 8(1). 
Setiawan, M, Emvalomatis, G, Oude Lansink, A (2015a) Price Rigidity and Industrial Concentration: Evidence from the Indonesian Food and Beverages Industry, Asian Economic Journal, Vol. 29(1)

Setiawan, M, Indiastuti, R., Destevanie, P. (2015b) Information Technology and Competitiveness of
Small and Medium Enterprises in Cimahi, International Journal of Entrepreneurship and Small Business, Vol. 25 No 4

Shirazi, Javad Khalilzadeh (1974) Market structure and price-cost margin in United Kingdom manufacturing industries, The Review of Economics and Statistics, 56(1), pp. 67-76

Table 1. Descriptive statistics of the variables from 2011-2014

\begin{tabular}{lrrrr}
\hline \multicolumn{1}{c}{ Variable } & Mean & $\begin{array}{c}\text { Standard } \\
\text { Deviation }\end{array}$ & Min & Max \\
\hline CR4 & 0.259 & 0.220 & 0.061 & 1.000 \\
HHI & 0.066 & 0.143 & 0.004 & 1.000 \\
PCM & 0.121 & 0.397 & -0.999 & 0.951 \\
Size (Log of VA) & 16.121 & 1.680 & 8.899 & 20.480 \\
COR & 2.961 & 0.161 & $7.6 .10^{-5}$ & 198.690 \\
N-Subsectors & 10 & 10 & 10 & 10 \\
\hline
\end{tabular}

Table 2. Trend of The Technical Efficiency Score and Industrial Concentration

\begin{tabular}{lllc}
\hline Year & $\begin{array}{c}\text { Average } \\
\text { PCM }\end{array}$ & $\begin{array}{c}\text { Average } \\
\text { CR4 }\end{array}$ & $\begin{array}{c}\text { Average } \\
\text { HHI }\end{array}$ \\
\hline 2011 & -0.547 & 0.445 & 0.151 \\
2012 & -0.341 & 0.673 & 0.243 \\
2013 & 0.306 & 0.171 & 0.034 \\
2014 & 0.089 & 0.269 & 0.057 \\
\hline \multicolumn{4}{l}{ Source: Indonesian BPS and authors' calculation }
\end{tabular}

Table 3. Results of the Relationship Between Industrial Concentration and Price-cost Margin

\begin{tabular}{lcc}
\hline \multirow{2}{*}{ Independent Variable } & \multicolumn{2}{c}{ Dependent Variable : AVERAGE PCM } \\
\cline { 2 - 3 } Intercept & Coefficients & Coefficients \\
& -0.184 & -0.517 \\
CR4 & $(0.315)$ & $(0.311)$ \\
& $-1.141^{* * *}$ & \\
HHI & $(0.251)$ & $-1.477^{* * *}$ \\
& & $(0.389)$ \\
CLR & & $0.019 * * *$ \\
& $0.017^{* * *}$ & $(0.004)$ \\
$\mathrm{R}^{2}$ & $(0.0039)$ & 0.764 \\
F-statistics & 0.796 & $5.390^{* * * *}$ \\
\hline
\end{tabular}

Source: own calculation 